www.periodicos.unimontes.br/index.php/caminhosdahistoria

\title{
O HOMEM E A NATUREZA: BOIADEIROS E BOIADAS NO NOROESTE PAULISTA
}

\author{
Natalia Scarabeli Zancanari ${ }^{1}$ \\ Felipe Bastos Maranezi ${ }^{2}$
}

Resumo: Este artigo busca expor parte da complexidade do conhecimento dos boiadeiros que conviviam com as diversas paisagens presentes pelos caminhos nos anos de 1915 a 1940. Desta maneira, analisamos a prática do manejo do gado, entendendo-a como inserida nas diversas paisagens relacionadas aos marcos referenciais. Indagamos ainda sobre os significados atribuídos à natureza no percurso das viagens, o que esta influenciava diretamente na definição de roteiros das comitivas, valorizando o conhecimento dos boiadeiros. Assim, buscou-se descrever o universo cultural do condutor e peão de boiadeiro dentro da estrutura e cotidiano de seu trabalho. Neste âmbito, a interpretação de dados bibliográficos proporcionou uma discussão sobre as adaptações no modo de vida desses sujeitos referente ao conhecimento adquirido nas viagens e sua influência deixada nos lugares por onde passavam. O estudo enfatiza a contribuição desses sujeitos não apenas na configuração social e econômica, mas também cultural da região do Noroeste paulista.

Palavras-chave: Estrada Boiadeira; peão de boiadeiro; modos de vida; natureza; São Paulo.

Abstract: This article seeks to expose part of the complexity of the knowledge of the cowboys who lived with the different landscapes present in the paths from 1915 to 1940. In this way, we analyze the practice of cattle management, understanding it as inserted in the different landscapes related to benchmarks. We also asked about the meanings attributed to nature in the course of the trips, which directly influenced the definition of itineraries of the delegations, valuing the knowledge of the cowboys. Thus, we sought to describe the cultural universe of the driver and cowboy pedestrian within the structure and daily life of his work. In this context, the interpretation of bibliographic data provided a discussion about the adaptations in the way of life of these subjects regarding the knowledge acquired in the trips and their influence left in the places where they passed. The study emphasizes the contribution of these subjects not only in the social and economic configuration, but also in the cultural region of the Northwest of São Paulo.

Keywords: Boiadeira road; cowboy pawn; lifestyle; nature São Paulo.

\section{Introdução}

As histórias contadas pelos peões de boiadeiro e condutores ${ }^{3}$ que viajavam pela Estrada Boiadeira ${ }^{4}$ conduzindo o gado, por meio das entrevistas, entre outras fontes, revelam

\footnotetext{
${ }^{1}$ Doutoranda em História do Programa de Pós- Graduação em História. Universidade Estadual de Maringá/PR, Brasil. E-mail: nataliazancanari@yahoo.com.br. ORCID: https://orcid.org/0000-0002-4253-2086.

${ }^{2}$ Doutorando em História do Programa de Pós- Graduação em História. Universidade Estadual de Maringá, Maringá/PR,Brasil. E-mail: felipebmaranezi@hotmail.com. ORCID: https://orcid.org/0000-0003-1271-3430.
} 
hábitos e costumes peculiares que se moldam de acordo com o modo de vida que esses sujeitos levavam. As regras existentes nas comitivas, os laços de amizades construídos durante a passagem da comitiva pelas fazendas, os pontos de pouso, a travessia de um rio, entre outras situações, exigiam dos peões conhecimento e habilidades principalmente na lida com o gado. Este modo de viver organizava o espaço onde conviviam no dia a dia. Tratavamse de práticas cotidianas que mostravam as peculiaridades da vida do boiadeiro as quais se transformaram em marcos de sua cultura.

O desafio estava em descobrir como se constituía o cotidiano desses sujeitos durante as viagens por territórios distantes das cidades. O estudo dos peões de boiadeiro se deu por meio de indícios de sua cultura, experiências e histórias narradas. Essas experiências se revelavam ao longo dos trajetos percorridos pelas comitivas de peões de boiadeiro a fim de conduzir o gado, principalmente, nos caminhos do Noroeste paulista até a cidade de Barretos. O percurso iniciava-se no Pantanal sul matogrossense com destino ao Estado de São Paulo, trajeto em que os peões vivenciavam variadas experiências, o que resultava em muitas histórias guardadas; colocando-nos a frente de um mundo possível, repleto de surpresas, de paisagens, de dificuldades e de outras cenas da vida.

Deste modo, indagamos ainda sobre os significados atribuídos à natureza no percurso das viagens, o que esta influenciava diretamente na definição de roteiros das comitivas, valorizando o conhecimento dos boiadeiros, apresentando questões que envolvem circunstâncias particulares e acontecimentos ricos em significados culturais, revelando, no simbolismo da narrativa de algumas ações sobrenaturais, a forma como esses sujeitos se relaciona com o ambiente em que vive.

Assim, os hábitos e costumes na condução do gado pelos peões de boiadeiro, desenhados pelos traçados da Estrada Boiadeira são analisados desde a passagem das boiadas por esse percurso até o destino final, no Noroeste paulista. Esse ambiente revelou peculiaridades, habilidades, crenças exigidas para este trabalho em comitivas e suas dificuldades, sendo possível, na análise do cotidiano, apreender elementos que demonstrassem também a relação entre o homem e os elementos da natureza.

\footnotetext{
${ }^{3}$ A figura do condutor e peão de boiadeiro difere dentro da comitiva, existindo uma hierarquia, em que o condutor geralmente é o dono da tropa e responsável pela entrega do gado, respondendo por toda a comitiva, enquanto o peão de boiadeiro é o homem contratado para designar certas funções dentro comitiva. Deste modo, no decurso da pesquisa, esta distinção aparece, pois diferentemente da leitura do senso comum de que todos são peões de boiadeiros, no interior da comitiva esta distinção é clara.

${ }^{4}$ A Estrada Boiadeira a que a pesquisa se refere é a Estrada Boiadeira do Taboado, cujo traçado se estende do Porto do Taboado (lado sul de Mato Grosso) até o Noroeste paulista, no Estado de São Paulo, mais precisamente até a cidade de Barretos.
} 


\section{Natureza e o peão de boiadeiro}

A partir da vivência do boiadeiro e de sua relação com a natureza, são construídas orientações espaciais durante a condução do gado. Essa relação se encontra baseada na forma de comunicação entre moradores das fazendas e boiadeiros, como também em marcos referencial da paisagem presente, por exemplo, nas marcas dos pontos de pouso, que eram utilizadas como roteiros para a viagem em comitivas.

As comitivas têm sido realizadas há séculos no transporte de mercadorias, possuindo importância histórica, cultural e socioeconômica, estando associadas às ocupações humanas em diferentes épocas e paisagens, como no caso do Estado de Mato Grosso e da região Noroeste paulista. Durante as viagens, o boiadeiro atravessava, com cerca de mil cabeças de gado, uma área de vegetação que ia desde campo-cerrado no Mato Grosso a matas fechadas no interior paulista com apenas um caminho aberto para a passagem do gado. Esses caminhos eram conhecidos como corredores ou estradas boiadeiras que cortavam o Brasil permitindo a ligação entre localidades distantes.

Os anos de 1915 a 1940 são o foco da pesquisa à medida que possibilitam entender a abertura da Estrada Boiadeira, cujo gado, a partir desse período, era conduzido até o frigorífico de Barretos. Naquele momento, passavam por esse traçado milhares de cabeças de gado, o que contribuía para a povoação do Noroeste Paulista. Contudo, vale ressaltar a discussão de um período anterior a essas datas, em 1906, pois contribuiu para entender a constituição da Estrada do Taboado ${ }^{5}$, primeiro traçado da Estrada Boiadeira.

As especificidades e particularidades da natureza se encontram intimamente ligadas à presença humana na região em estudo, marcando a integração com as atividades de trabalho desenvolvidas pelos peões de boiadeiro. Essas atividades relacionadas à pecuária expressam uma relação do peão d e boiadeiro com a natureza, a partir do convívio interligado com animais e plantas, bem como com outras pessoas. Nesse caso, como sugere Joaquim Rondon da Rocha Azevedo, ao discutir a identidade pantaneira e sua relação com a natureza:

As características da identidade pantaneira, do homem pantaneiro, e seu apego ao território são fatores decisivos na formação da paisagem da região (...). Esta, por sua vez, é determinante na estruturação desta identidade denotando um processo interativo, co-evolutivo, em que os elementos naturais e humanos não podem ser entendidos isoladamente (2002, p. 72).

\footnotetext{
${ }^{5}$ A Estrada do Taboado tinha seu traçado do Porto do Taboado até a cidade paulista de Jaboticabal. Essa estrada veio mais tarde a se chamar de Boiadeira, mudando seu curso para a cidade paulista de Barretos.
} 
Os contatos iniciais entre o peão de boiadeiro e a natureza ocorreram no intuito de sobrevivência desse homem. Assim, o conhecimento do meio natural auxiliou-o durante as viagens na percepção do local, como também das ervas para curar doenças, dos pontos de pouso para se proteger do frio e até mesmo de fazendas que ofereciam alguma comida para esses peões de boiadeiro.

A atividade econômica, como a pecuária, integrava essa relação do peão de boiadeiro com a natureza; a própria comitiva dependia dessas ações para seu trabalho e para que o gado chegasse até o destino final. Neste caso, como destaca Marcos Lobato Martins, o homem era motivado por interesses que atendiam à sua necessidade de sobrevivência em meio à natureza:

(...) para numerosas sociedades e grupos sociais, a natureza é mais do que mero meio de subsistência. Ela está diretamente ligada ao sistema de crenças e de conhecimento de maneira que ela é um recurso sociocultural. Para diversos povos, na natureza estão inscritas as mais básicas noções de autodeterminação, de articulação social, de vivência e crenças religiosas, para não falar da existência da sociedade (2007, p. 35).

Durante as viagens, o peão de boiadeiro se utilizava das propriedades oferecidas pela natureza. "Além da madeira, o sertanejo aproveita outras partes das plantas (folhas, ramos, frutos, leite, raiz) para compor uma dieta alimentar e manipular os remédios caseiros e as simpatias" (MEYER, 1998, p. 181).

Deste modo, é importante entender como uma determinada cultura se apropria de elementos da natureza. Como narrado, os peões de boiadeiro utilizavam de ervas que eram retiradas da natureza e de determinados lugares. Essas plantas eram relacionadas de acordo com a utilidade, sem a preocupação desses sujeitos em nomeá-las e classifica-las cientificamente. Entendiam que passar a maior parte do tempo conduzindo a boiada era um trabalho que significava a própria vida da maioria deles. Por meio de seu ofício, constituíam modos de vida particulares que atendiam às suas necessidades em vista do meio em que viviam.

Por meio da vivência do boiadeiro e de sua relação com as paisagens, iam sendo construídos laços de amizades com os fazendeiros que tinham suas propriedades à beira das estradas boiadeiras que significavam formas de orientação espacial desses peões durante a condução do gado. As cercas ou casas serviam de pontos que indicavam a passagem do caminho também eram marcos para o conhecimento dos caminhos.

Ao estudar as comitivas pantaneiras em tempo recente, Maria Odila Ferreira Leite (2010) aponta tipos de orientações espaciais utilizadas pelos peões de boiadeiro. A autora refere-se às marcas feitas em árvores pelos próprios boiadeiros com uso de facas. Essas 
marcas ajudam as comitivas na indicação do caminho correto da estrada. Afirma ainda que acontecimentos durante a viagem também poderiam tornar-se referências para os caminhos, tais como: a laçada de uma rês arribada, uma queda de cavalo, ou mesmo histórias de assombração. Essas lembranças ajudavam na orientação do caminho correto.

Os marcos apontados por Maria Odila Leite (2010) estão intimamente ligados à atividade da pecuária. Segundo a autora, a disponibilidade de água também pode mudar o roteiro de viagem, pois, como no passado, ainda é de suma importância para o preparo das refeições, o banho, como também para que o peão e o gado possam se revigorar para seguirem caminho. Todas essas condições, ligadas à natureza, influenciaram no roteiro de transporte da boiada pela Estrada Boiadeira.

A vivência e a experiência do ser humano com a natureza implicam aspectos objetivos e subjetivos que estão presentes no cotidiano desses homens. Assim, o cotidiano da comitiva era revelado, segundo as fontes, por meio de uma multiplicidade de relações humanas com elementos presentes na natureza, como, por exemplo, na descrição do caminho, das águas, dos animais e do clima; relações marcadas, por exemplo, pela oralidade. Essas descrições se encontram cheias de cores, dando vivacidade ao fato narrado, como afirma Mônica Meyer: "Pela poeira da estrada se avista a boiada. Pela cor do rio se faz a leitura dos ciclos da natureza" (1998, p. 123). As sensações experimentadas se encontram na memória, momento em que acendem lembranças de vivências dos fatos passados.

Neste caso, as narrativas são entremeadas pelas descrições da memória, pela imaginação, pelo vivido nas estradas boiadeiras. As interações entre o visto e o vivido pelos peões de boiadeiro contribuem na construção de sua imagem e de seu valor, carregado de sentimento e memória. Sobre essa questão, as considerações de Marilena Chauí são reveladoras: “A memória é uma atualização do passado ou a presentificação do passado e é também registro do presente para que permaneça como lembrança” (2000, p. 128).

O pó da estrada fazia com que o peão de boiadeiro conhecesse as estações do ano, assim como a lama nas estradas marcava as épocas de chuva. Essas observações e conhecimentos ajudavam o boiadeiro a estudar os melhores caminhos para passagem do gado em tais épocas. Percebemos, assim, que ritmo de vida desses homens fazia sintonia com o ciclo dos fenômenos naturais.

Desse modo, o ciclo das águas ditava o tempo exato de levar os animais de uma região para outra devido às enchentes nos locais, como também evitava atoleiros de gado durante a passagem da comitiva nas estradas. Essas observações e informações traduziam um 
conhecimento empírico do peão de boiadeiro que vivia uma relação íntima com o mundo natural.

No período estudado, o Pantanal e os campos da Vacaria eram regiões produtoras de gado (e continuam a ser), e de lá os animais eram vendidos para outros locais principalmente para o Estado de São Paulo. O transporte do gado nessas regiões era feito por meio de comitivas, formadas por peões de boiadeiro acostumados a conduzir o gado a longas distâncias. Esses condutores possuíam experiência necessária para os deslocamentos dos bovinos - desde o primeiro contato com o fazendeiro, dono das boiadas -, como também para as adversidades ocorridas nas viagens e o destino final, com a entrega do gado.

As características da paisagem revelavam as estações de seca e chuvas, podendo o peão modificar seu roteiro de viagens, conduzindo o animal para outro local. Ainda hoje, o Pantanal é inundado em determinadas áreas durante as épocas de chuva, ficando a cargo dos peões de boiadeiro a condução dos animais para outros lugares protegidos das enchentes. É esse ciclo das águas que regula a vida da fauna e da flora, assim como a do peão de boiadeiro que nos meses de chuva procura lugares para abrigar o gado. O ritmo imposto pelos climas influencia as formas de vida e, também, de certa forma, as atividades cotidianas desses peões de boiadeiro. As estações são bem acentuadas. No tempo da seca, avista-se uma grossa nuvem de poeira se espalhando pelos pastos e sítios. No contexto da pesquisa, as manadas avançavam pelos estirões das estradas, tendo seus leitos pisados e repisados pela gadaria, obediente aos gritos e laços do peão de boiadeiro, quebrando o silêncio das matas com os sinos, chocalhos e mugidos.

O ritmo das águas nos pantanais sugere a ideia de ciclos demarcados pelas épocas de cheia - vazante - seca, o que possibilita o surgimento de saberes específicos que permitiram por mais de três séculos a sobrevivência da pecuária.

$\mathrm{Na}$ análise do objeto específico, observamos que, para o funcionamento da comitiva, eram necessárias regras. Logo ao amanhecer, por exemplo, as tarefas se iniciavam (recolher e fazer a contagem do gado; comer; beber; preparar as tralhas) cumprindo sempre um ritual de preparação para reiniciar a viagem. Pelo caminho, a observação do comportamento dos bovinos indicava o momento de uma parada para o descanso, ou seja, o momento em que os animais revelavam sinais de cansaço. Quando um boi começava a deitar, os outros faziam o mesmo, o que era sinal de cansaço, sendo necessária a atenção dos peões de boiadeiro, como também a procura, ainda com o dia claro, do local de pouso previsto no roteiro, para que os boiadeiros e a boiada descansassem. 
Além dessa sintonia com os animais, o caminhar das comitivas revelava um tipo de saber do boiadeiro que vivia em contato com o meio e aprendia a decodificar os signos naturais. Essa relação com o mundo natural era fundamental para os peões de boiadeiro, pois era por meio dessa leitura da paisagem que moldavam parte da história do sul de Mato Grosso e do Noroeste paulista. Conforme Meyer: "Quando o passarinho e a cigarra aparece para reproduzir, quando os sapos começam a coaxar significa que as chuvas se aproximam". Esses signos naturais permitiam o peão d e boiadeiro fazer uma previsão do tempo. Assim, o ritmo de vida do boiadeiro fazia "sintonia com o ciclo dos fenômenos naturais" (MEYER, 1998, p. 145-146). A leitura do volume de água dos rios e córregos presentes nos traçados das estradas boiadeiras representava o período das estações.

Segundo Meyer, o cotidiano do vaqueiro é absorvido pela jornada do dia em que ele se mantém observando qualquer comportamento do gado. $\mathrm{O}$ autor afirma que "não dá tempo para se acostumar, mas dá tempo para aprender" (IDEM, 1998, p. 153). Essa sabedoria com o gado era aprendida na lida, na capacidade do peão de boiadeiro em observar o comportamento do gado, medindo a marcha da boiada, mantendo-a dentro de uma ordem, para que se evitassem acidentes, estouros e fugas. Assim, “o vaqueiro, pela própria especificidade do trabalho, estabelece uma relação de constância com o mundo natural” (MEYER, 1998, p. 155). Ao montar, ele cria uma relação de intimidade com o animal, pois ele doma, domestica, manipula o animal com laços, além de colocar cabrestos como preparativos para montar (arreios, cabrestos, pelego, selas). Alimentação, descanso do animal, afago, são relações de dependência e intimidade entre o homem e o animal.

Esse conceito de paisagem como processo cultural apresenta uma importante referência para o estudo sobre o peão de boiadeiro e suas relações com o ambiente em que vive. Conforme Ulpiano T. Bezerra de Meneses, "é considerando a paisagem uma estrutura de interação que se tem sua verdadeira natureza cultural” (2002, p. 32). Ainda, para o autor, não basta "supormos um objeto (uma extensão da superfície da terra), a ação humana que o transforma e a integração (material ou simbólica) que se estabelece" (p. 31).

Neste caso, o papel das paisagens para os grupos humanos se traduz no significado dado pela experiência vivida por cada grupo. O contato do peão de boiadeiro com as paisagens pode ser chamado de: "fenômeno integrado, como um fluxo contínuo de interação, cultura e ambiente, que transforma ambos" (LEITE, 2010, p. 53).

Os contatos iniciais entre o homem e a natureza foram interagindo em função da necessidade desses homens em sobreviver nas matas e cerrados, como também para uma boa travessia do gado. Esse contato estava inteiramente ligado à natureza. O homem é parte 
integrante desse universo em que suas ações são motivadas a atenderem aos interesses de sua necessidade de sobrevivência. Para as diferentes sociedades e grupos sociais, a natureza se encontra ligada ao sistema de crenças e de conhecimento, sendo um recurso sociocultural. Essa relação entre homem e natureza constitui na adaptação e apropriação em um ambiente que se impõe e determina o ritmo da vida, como a dos peões de boiadeiro, o qual se encontra ligado às transformações da natureza. Ou seja, definido pelo ritmo das águas, pela marcha do gado, pelas ervas medicinais, fatores estes intimamente ligados ao mesmo universo.

Nesse sentido, o homem que vive no meio rural desenvolve habilidades e atividades que permitem sua sobrevivência no meio. A linguagem, as crenças e as tradições que, ao longo do tempo se mantêm vivas por meio da cultura, revelam a relação entre o peão de boiadeiro e a natureza. Em certa medida, esse homem simples traz em si todo o conhecimento das particularidades do mundo do qual faz parte. O homem que convive com esse ambiente percebe essa relação com o mundo que se insere, interferindo no seu modo de viver. Essa interação entre homem e natureza - pássaros, águas, árvores - faz a paisagem do lugar; tornaa o espaço de ribeirinhos, sertanejos, boiadeiros, representado no conviver e habitar das matas fechadas.

A natureza contribui para que o homem inserido nesse espaço adquira conhecimento que o prepare para as adversidades que o próprio meio natural lhe impõe. Observar e contemplar são maneiras do peão de boiadeiro lidar com a natureza e suas transformações. Desse modo, a partir do momento em que o peão de boiadeiro se coloca a perigo, seja ele de boi arribado, de estouro de boiada ou mesmo de algum animal ameaçado à frente, mentalmente já começa a elaborar estratégias de continuidade, utilizando- se do próprio conhecimento que adquiriu na natureza.

Por essas razões, percebemos que as relações estabelecidas entre homem e natureza estão basicamente centradas nos próprios valores, sentimentos e comportamentos que se refletem no grupo social inserido. No caso, a ação do peão de boiadeiro se encontra essencialmente em sua sobrevivência pelos caminhos, conduzindo a boiada, como também no desenvolvimento de seu trabalho nas comitivas.

\section{A travessia do rio}

O transporte dos animais ocorria de modo lento, o que causava desgaste físico ao animal e ao peão de boiadeiro. Ambos eram obrigados a atravessar o rio de um lado para o outro, a nado. Mais ao sul do rio Paraná houve vezes em que se perdia grande número de 
boiadas. No período de navegação do Rio Paraná e seus afluentes, de início a relação se estabelecia por meio da travessia do gado de Mato Grosso para São Paulo e, mais tarde, na compra de produtos da região: “em função de sua demanda, como: peles de animais silvestres e erva-mate, ou no atendimento às necessidades de sertanejos que viviam na região, nos pousos de boiadas em seu trajeto no Sul de Mato Grosso" (ZILIANI, 2010, p. 103).

O intenso fluxo de boiadeiros era lugar privilegiado para a observação das paisagens, assim como das comitivas que transitavam sobre o traçado da Estrada Boiadeira. A travessia do rio mais ao sul "possibilitava um vislumbre de um rio que, de tão largo, mais parece um mar e que, deslizando por entre ilhas maravilhosas, vai proporcionando ao viajante, a visão das cenas mais deslumbrantes e inéditas" (ZILIANI, 2010, p. 111).

O animal chegava no Estado de São Paulo magro e cansado pelas longas viagens e, ao atravessar o rio encontrava pastagens verdes para recuperar seu peso, nas grandes fazendas de invernadas. Era ali que descansava para a última etapa que seriam os frigoríficos. Desse modo, "na franja pioneira, essas invernadas encontram-se na posição geográfica mais favorável para receber as boiadas emagrecidas (...). Depois da engorda, os animais cobrem facilmente o trajeto que o separa de Barretos" (MONBEIG, 1984, p. 305). Nesse caso, a região Noroeste paulista se tornava a principal via de penetração para o gado vindo do sul de Mato Grosso. Na observação da paisagem natural da região que se localizava às margens do Rio Paraná, no lado paulista era possível apreciar fauna e flora, em que se encontravam plantas de todas as espécies, árvores seculares, flores variadas e a predominância do verde das matas. A fauna também se destacava nessa região:

Garças róseas e brancas, sempre em bando, offerecem uma nota sugestiva entre a innumeras e originaes aves de que é farta essa região. Jacarés, macacos, capivaras são vistos na viagem e algumas vezes até o especimenn é percebida no trajeto ao longo do Rio Paraná (CUSPMT,1938 apud ZILIANI, 2010, p. 111).

As travessias do gado estão sempre presentes nas narrações dos condutores e peões de boiadeiro. Como salientado, a travessia constituía-se num momento difícil para o peão de boiadeiro, exigindo habilidades do condutor e de sua comitiva para vencer os obstáculos, ao serem capazes de reafirmar sua capacidade e destreza para enfrentar o meio.

Os relatos de condutores de gado sobre a passagem das comitivas em rios revelam as habilidades desses sujeitos diante das dificuldades do cotidiano.

Os vaqueiros [...] contaram que as piranhas são muito prejudiciais quando se passa um grande rebanho no rio. Nessa ocasião os homens cutucam uma rês até entrar no rio. Como as piranhas seguem a corrente do rio com o animal morto, as outras reses podem ser passadas com certa segurança e sem muito receio de ocorrer o "estouro da boiada". (JONES, 1950, p. 359). 
Nas descrições dos entrevistados, entre outras fontes, é possível observar a balsa como elemento de transporte nos rios, mas quando elas não existiam os animais seguiam a nado. A narrativa a seguir descreve as técnicas utilizadas pelos peões para atravessar o rio sem molhar as roupas e o perigo da perda da boiada.

Os peões sofriam muito para chegar ao ponto de pouso, principalmente porque se molhavam e molhavam também sua tralha de montaria. Esse jeito de levar as roupas eram técnicas inventadas por eles de modo que não ficassem encharcados durante a viagem. Nos dias de chuvas intensas, a comitiva não parava, o burro era pego e encilhado mesmo na chuva. Contudo, durante o período de estiagem, a situação se invertia e a escassez de água era mais uma preocupação dos boiadeiros, não somente para consumo próprio, mas também para a boiada e a tropa.

Durante a seca, havia muita poeira na estrada, sendo essa época do ano a mais difícil de se encontrar água para tomar banho. "Das tardes quentes de agosto suor do meu rosto coberto de pó.” Em alguns trechos da música, na referência à parte sul matogrossense, é possível perceber que no tempo da seca andavam-se dois dias e não se encontrava água, sendo a única coisa a fazer encontrar uma fazenda que tivesse açude para que o gado e o peão de boiadeiro pudessem matar a sede.

As observações das estações climáticas feitas pelos peões de boiadeiro definiam e modificavam sua viagem. Segundo Goulart (1961), o mês de março era propício para as longas viagens, pois as pastagens estavam ainda verdejantes devido ao fim das estações de chuva e não havia o perigo de as estradas se transformarem em atoleiros prejudicando a passagem do gado. A depender da estação do ano, o nível das águas impunha maiores dificuldades à passagem do rio, o que às vezes aumentava o tempo do percurso.

O período sem chuvas ocasionava a falta de água em alguns trechos, problema que não ocorria na região Noroeste paulista onde existiam muitos córregos à beira da Estrada Boiadeira. Deste modo, para a execução do ofício das comitivas de boiadeiros não era necessário somente o conhecimento dos rios onde atravessavam com a boiada, mas exigia se também do viajante a habilidade no transporte desse gado durante a travessia para que ele chegasse saudável ao seu destino. Nas marchas, com muitas de cabeças de gado, as comitivas enfrentavam adversidades de acordo com as estações do ano, como enchentes, cheias, vazantes e secas.

Ao passar esse desafio de atravessar o rio, a boiada prosseguia ainda que cansada junto aos peões de boiadeiro. Com dificuldade e a passos mais lentos, a viagem era retomada. 
Como narram os entrevistados, era possível ouvir o som do berrante na mão do ponteiro anunciando o reinício da marcha.

A condução do gado exigia muita paciência, sendo esta uma característica marcante da personalidade dos boiadeiros que era exercitada diariamente, pois havia a necessidade de se conduzir o gado a passos lentos para que este chegasse saudável ao seu destino. O gado e a tropa seguiam pastando na direção orientada pelo condutor e ponteiro. Assim, qualquer perigo na estrada era avisado pelo ponteiro aos outros companheiros que vinham logo em seguida com a boiada.

\section{Considerações finais}

A partir da vivência observada no trabalho que os boiadeiros realizavam (e ainda realizam) no transporte do gado de uma região a outra foi possível notar a riqueza do conhecimento da natureza, as técnicas utilizadas no manejo com o gado, a capacidade de observação desses sujeitos, bem como a importância de seu viver como percepção sobre o valor cultural exercido durante sua atividade e na transformação dos lugares por onde passavam, ou seja, entre o sul de Mato Grosso e o Noroeste Paulista.

Além das técnicas necessárias para o desempenho de seu trabalho, os boiadeiros, nas comitivas, possuíam rituais cotidianos para sua organização, os quais à primeira vista pareciam ser simples, mas que foram denotando a sua complexidade. Esses homens que percorriam a Estrada Boiadeira estavam imbuídos de conhecimentos, experiências e valores éticos, tal como pode ser observado nos momentos em que ocorria alguma intempérie, como, por exemplo, uma doença dos peões, ou mesmo nas regras da cozinha. Isto se incorpora à prática de um diversificado sistema de regras, mitos, rituais que evidenciam a cultura dos peões de boiadeiro e condutores.

Durante as viagens em comitivas pela Estrada Boiadeira, esses sujeitos desenvolviam conhecimentos tradicionais, originando um processo de adaptação para a sobrevivência nas diferentes condições do ambiente, como o contato com a natureza desenvolvendo uma forma de vida própria. O cotidiano de trabalho era repleto de desafios, surpresas, perigos e cenas de um viver característico. Acerca disso, procuramos apontar os conhecimentos adquiridos na natureza e os fluxos interpretativos de seu modo de vida que deram origem à (re) construção da identidade de "ser peão boiadeiro", mais ainda que a de "ser condutor".

No decorrer do texto, o leitor pôde perceber que na região e período estudado as palavras "condutor" e "peão de boiadeiro" aparecem para especificar o tipo de trabalho que 
cada sujeito realizava dentro das comitivas que formavam uma hierarquia. Eram homens que viviam de acordos de trabalho no desenvolvimento temporário de atividades voltadas à pecuária. Desse modo, o estudo dos condutores e peões de boiadeiro evidenciou a diversidade de relações tecidas por esses homens e a importância que eles tiveram para a dinâmica interna da região Noroeste paulista e sul de Mato Grosso. São seres indissociáveis, com modos de vida peculiar que se formam de acordo com a atividade desenvolvida durante o trabalho. Homens com distintos anseios, angústias, sentimentos, modos de viver, sobreviver e adaptarse.

\section{Referências bibliográficas}

AZEVEDO. Joaquim R. R. A conservação da paisagem como alternativa à criação de áreas protegidas: Um estudo de caso do Vale do Rio Negro na região do Pantanal-MS. São Paulo, 2002. Dissertação (Mestrado em Ciência Ambiental)-Universidade de São Paulo.

CHAUÍ, Marilena. Convite à filosofia. São Paulo:Editora Ática, 12 ed, 2000.

GOULART, José Alípio. Tropas e Tropeiros na Formação do Brasil. Rio de Janeiro. Editora: Conquista, 1961.

JONES, Clarence F. A Fazenda Miranda em Mato Grosso. Revista Brasileira de Geografia. Sumário do número de julho-setembro de 1950.

LEITE, Maria O. F. Comitiva de boiadeiros no Pantanal Sul-Mato Grossense: modo de vida e leitura da paisagem. São Paulo, 2010. Dissertação (Mestrado em Ciência Ambiental)Universidade de São Paulo.

MARTINS, Marcos L. História e Meio Ambiente. São Paulo: Annablume. Faculdades Pedro Leopoldo, 2007.

MENESES, Ulpiano T. B. A paisagem como fator cultural. In: Yázigi, Eduardo (org.). Turismo e Paisagem. São Paulo: Contexto, 2002.

MEYER, Mônica A. A. Ser-tão natureza: a natureza de Guimarães Rosa. Campinas, 1998.Tese (Doutorado em Ciências Sociais)- Instituto de Filosofia e Ciências Humanas daUniversidade Estadual de Campinas.

MONBEIG, Pierre. Pioneiros e fazendeiros de São Paulo, São Paulo, Editora Polis 1984.

ZILIANI, José Carlos. Colonização: Táticas e estratégias da Companhia de viação São Paulo Mato Grosso (1908-1960). Assis, 2010. Tese (Doutorado em História)-Faculdade de Ciências e Letras de Assis, Universidade Estadual Paulista. 